\title{
From pathology to invisibility: age identity as a cultural construct in vampire fiction
}

\author{
Marta Miquel-Baldellou \\ Universitat de Lleida \\ mmiquel@dal.udl.cat
}

\begin{abstract}
A diachronic analysis of the way the literary vampire has been characterised from the Victorian era up to the contemporary period underlines a clear evolution that seems particularly relevant from the perspective of ageing studies. One of the permanent features characterising the fictional vampire from its origins to its current manifestations in literature is precisely the vampire's disaffection with the effects of ageing in spite of its old chronological age. Nonetheless, even though the vampire's appearance does not age, the way it has been presented in literature has significantly evolved from a remarkable aged look during the Victorian period in John Polidori's "The Vampyre: A Tale" (1819), Joseph Sheridan Le Fanu's Carmilla (1872) or Bram Stoker's Dracula (1897) to young adulthood in Anne Rice's An Interview with the Vampire (1976) and Charlaine Harris' Dead Until Dark (2001), adolescence in Stephenie Meyer's Twilight (2005-2008), and even childhood in John Ajvide Lindquist's Let the Right One In (2004), thus underlining a significant process of rejuvenation through time despite the vampire's apparent disaffection with the effects of ageing. This article shows how the representations of the vampire in literature reflect a shift from the embodiment of pathology to the invisibility, or the denial, of old age and how this, in turn, reflects cultural conceptualisations and perceptions of ageing.
\end{abstract}

Keywords: discourses of ageing, vampire fiction, cultural construct, pathology, invisibility 


\section{Introduction}

As has been traditionally depicted in different cultural manifestations such as literature and cinema, the vampire can be defined as an apparently human being that does not look its chronological age and is not affected by the passage of time or the effects of ageing. In fact, the vampire conceals its blatant old age under the guise of youth, thus subverting any socially and culturally constructed standards respectively attached to youth and old age. In its capacity to deceive as well as in its ability to challenge standards, the figure of the vampire has conventionally been perceived as an abject embodiment of fear, otherness, and evil. Significantly enough, in the domain of literature the vampire mostly began to proliferate in many gothic narratives published during the Victorian period, which was a time when, according to critics such as Teresa Mangum, ageing also became an issue of widespread interest and concern in different fields of knowledge. Consequently, it can be argued that the concern about ageing in the Victorian period seemed to find its reflection in the proliferation of vampire narratives. In fact, it can be claimed that, to Victorians, the literary vampire became the quintessential cultural embodiment of old age, as it personified many tenets related to the discourses of ageing that prevailed at the time.

In the Victorian period, interest in old age was perceived in the creation of the elderly subject as a category in the medical discourse as well as in the increasing need for public provision in old age. In this respect, Karen Chase refers to the Victorian concern with ageing stemming from the fact that, even though "modernisation did not greatly extend the age of mortality [...] the decline of mortality rates in childhood and in youth swelled the numbers at the other end" (2009: 4). Consequently, although the age of mortality did not sharply rise throughout the century, owing to the gradual improvement of infant and youth mortality more people could survive past childhood and thus grow into subsequent phases of the life course, including old age. Nonetheless, according to Robert Butler, the social disease of ageism also began to take shape at the time and old age became endowed with judgements of mental or even moral incapability in addition to presumptions of declining health. As a matter of fact, Thomas Cole comments on Victorian ageism through the connection between the scientific 'normalisation' of the aged and the lack of moral restraint that the aged were alleged to exhibit. In this sense, Cole argues that "the primary virtues of Victorian morality independence, health, success - required constant control over one's body and physical energies," while, conversely, the aged body became "a reminder of the limits of selfcontrol" and "came to signify what bourgeois culture hoped to avoid: dependence, disease, failure, and sin" (1983: 35). Hence, according to Cole, the aged represented a blind spot in the Victorian morality of self-control.

Likewise, public imagination had to contend with significantly contradictory images of ageing as a golden period in life as well as portraits of the aged as a mass of dependent people that began to menace the common welfare of the nation. In vampire fiction, vampires are often portrayed as heroic-antagonists or living-dead people, thus making use of contradictory terms which underline their oxymoronic nature, implying 
that they are endowed with a particular centrality while underlining their subversive nature at the same time. In this sense, in vampire narratives there is always a special concern not to trust appearances, as the physique of the vampire is by nature necessarily deceitful and its body does not match its chronological age. The figure of the vampire thus subverts any social need to categorise people according to age by means of their appearance but it also challenges the traditionally established Cartesian dilemma separating mind and body in old age. In fact, in his treatise on De Senectute, written c.65 BC, which, according to Karen Chase, still resounded in Victorian times, Cicero already pointed at this difference between mind and body in relation to youth and old age stating that: "I admire a young man who has something of the old man in him, so do I an old one who has something of a young man. The man who aims at this may possibly become old in body - in mind he never will" (2009: 59). Cicero thus already pointed at the differing effects that age may have on the body and the mind respectively, but he also defended the thesis that youth and old age should remain blended in the individual. This argument gave shape to the issue of mind-body schism which has pervaded ageing studies taking into consideration the different impact that, in some cases, age may respectively have on the mind and the body of the ageing individual. In this respect, the dichotomy between mind and body with regard to ageing was transposed and profusely explored in vampire fiction inasmuch as the vampire becomes an embodiment of both youth and age: in body, the vampire has a younger appearance than its chronological age while, in mind, the vampire is often portrayed as haunted by the old memories of an unusually protracted life even if its body remains untouched by the effects of time.

The fact of coming to terms with an individual's age also became quite an intricate matter in the nineteenth-century. As a matter of fact, those authorities responsible for deciding when to give aid to the elderly, as was the case with the Poor Law Guardians, did not label anyone only according to their chronological age. Instead, as Teresa Mangum asserts, individuals were assumed to be ageing when they manifested a set of conditions such as behavioural infirmity and physical deterioration. In this respect, Helen Small has also noticed the disparity existing between chronological age and the individual's physical conditions, which is a basic feature that characterises the figure of the vampire. In fact, to use Helen Small's words, "the age we feel is not necessarily the same as our calendrical age, nor is the same as how we are perceived, or how we register ourselves being perceived by others" (2007: 3). Given the complexity that asserting one's age entailed, medical studies began to focus on specific signs that would aid in categorising somebody as past its prime. In this respect, Stephen Katz has examined the impact of medical studies on the perception of old age in the Victorian period to the extent of considering that these perceptions paved the ground for the establishment of geriatrics and gerontology at the beginning of the twentieth century.

According to these medical studies, as Teresa Mangum further develops, the body gradually became fixed through the description of a set of biological signs that would ultimately be regarded as indicators of health or deterioration. In fact, medical approaches usually entertained two contradictory perceptions of how old age came 
about. According to the vitality model, old age was perceived as the gradual draining of energy and ability while, conversely, another theoretical model argued that old age suddenly emerged as a result of a grand climacteric, which involved a considerably abrupt physical collapse, loss of sexual identity, and mental deviance. This dichotomy between gradual or sudden transformation also features in fictional accounts of the vampire's process of coming into being, which varies from a gradual transition such as in the loss of innocence and initiation into vampirism of formerly 'angels of the house' like Laura in Joseph Sheridan Le Fanu's Carmilla (1872) or Lucy in Bram Stoker's Dracula (1897) to the almost instantaneous transformation of the living into the living dead, following baptism by another vampire as is the case with Renfield in Bram Stoker's seminal novel. Likewise, also from a medical perspective, Victorians became fond of perusing accounts which promised eternal youth and revealed ways of prolonging life. The proliferation of vampire narratives mirrored some of the eccentric experimental practices that took place at the time such as injections of crushed animal testicles, which aimed at rejuvenating and improving sexual performance, or the literal transfusion of blood, which again bore close resemblance with vampiric practices whereby the vampire nourishes on blood so as to attain an ever-lasting life, thus echoing contemporary medical practices of blood transfusions that promised to prolong youth and restore an ill body back to its healthy condition.

Likewise, from the perspective of gender, men and women were deemed aged according to different criteria, as men were often perceived as old in relation to their ability to work, whereas women were considered aged according to their reproductive capability rather than their productive potential (Mangum, 2005: 99). Hence, as a cultural reflection, in vampire fiction male and female vampires also come into being as a result of different circumstances which are necessarily conditioned by gender. Male vampires are often transformed into such in order to help other male vampires and increase their number and their power, whereas female vampires are usually transformed once they have gained insight into their own sexuality. As a matter of fact, Dracula chooses Renfield to be his servant and help him to achieve his evil purposes, while early poems and short pieces of literary vampire tradition often portrayed female vampires as temptresses. As cases in point, Johann Wolfgang von Goethe's "Die freundin von Corinth" ("The Bride of Corinth", 1797), Samuel Taylor Coleridge's "Christabel" (1797-1800), and Théophile Gautier's "La morte amoureuse" ("The Dead in Love", 1836) are early exponents of women's overt displays of sexuality enthralling young men. Women making advances towards men were necessarily depicted as female vampires, that is, as fallen women who dared trespass moral boundaries that were banned to pious and virtuous 'angels of the house'.

From a sociological perspective, the focus of attention on ageing in Victorian times also responded to the fact that birth rates began to drop while the population of those who were over forty started rising significantly. Even though life expectancy did not really increase during the Victorian period, there was the widespread impression that England was growing old exponentially as the number of aged people began to attract unprecedented attention in legislation, medicine and in literature to the extent that it is 
asserted that ageing could be interpreted as an eminently Victorian media event (Mangum, 2005: 102). Nonetheless, this prevalent feeling that the nation was growing aged contributed to an ongoing discourse of ageism in the sense that the elderly were perceived as past the age when society accepted dependency on individuals and, hence, the aged began to be held in contempt in a period particularly characterised by progress and production, scientific breakthroughs, and imperial expansion. Likewise, changes in legislation reduced pensions and pressured families to take care of their elders through private initiatives, while some cultural precepts at the time such as Thomas Malthus' theory of the growth of the population, Samuel Smiles' volume promoting self-help, or Charles Darwin's evolutionary theory also contributed to echoing the prevalent impression of the old as metaphorically draining the energy or the blood of their young relatives and, by extension, of the whole nation, thus drawing a parallel with the pervasive presence of the vampire in the narratives of the time.

Given this situation, there were social and cultural reasons prevailing that help to gain insight into the mistrust on the part of young people toward the old and the resentment on behalf of older people toward young adults. This generational divide remains at the core of nineteenth-century vampire narratives as the youth and the aged became suspicious of one another, given the fact that young people began to feel the aged kept them from what was their due, whereas the aged felt that they were being pushed out by those who were socially considered more 'productive'. It is in this cultural and social context that the figure of the vampire began to consolidate through different literary manifestations setting a precedent in Victorian times that would gradually evolve in subsequent characterisations of this archetype of the gothic in literature and cinema. The Victorian vampire thus arose from the biased view of old age on the part of the youth, since whatever the actual chronological age of the Victorian vampire, its victim is always young or even pubescent.

\section{The conceptualisations of ageing and its effects on the portrait of the vampire}

Nina Auerbach refers to the elasticity that characterises vampires arguing that, since we project on them refracted images of ourselves, each generation designs and typifies a particular kind of vampire. In this respect, a diachronic analysis of the way the literary vampire has been characterised from the Victorian era to our contemporary period underlines a clear evolution which seems particularly relevant from the perspective of ageing studies. From the generally considered to be the first vampire in English fiction, the Byronic aristocrat Lord Ruthven in John Polidori's "The Vampyre: A Tale" (1819) to the contemporary vampire heartthrobs in Stephenie Meyer's Twilight tetralogy (2005-08), literary and cinematic portrayals of the vampire have shifted significantly from focusing on parasitic personifications of wickedness and alterity that mostly threatened the establishment to the portrayal of heroic antagonists who no longer bear a hideous appearance but rather present a complex personality and a particularly acute sensibility that render them specially appealing to younger generations. 
Taking Dracula (1897) as a pivotal text, as well as considering a wide range of succeeding vampire narratives, evolving textual readings have enhanced and expanded different readings of the vampire myth from different literary theories such as psychoanalysis, gender studies, postcolonialism, postmodernism, and cultural studies. In the process, the vampire has been envisioned as the incarnation of deviant sexuality, a forerunner of the new woman, the hero of postnational identities, a postmodern existentialist hero, or as a profitable cultural commodity for mass consumption. In this respect, critic William Hugues underlines the evolution of this literary myth outlining the metamorphosis of the vampire from a Victorian displacement phenomenon, inherently negative and repulsive, to an eminently positive enhancement of sensual life which is likely to appear as desirable to contemporary audiences. Nonetheless, the diverse readings of the literary vampire through time have scarcely taken into consideration the importance that cultural conceptualisations of ageing have exerted on the evolution of the fictional vampire and its characterisation, especially bearing in mind the vampire's virtual incapacity to age and its ability to defy the passage of time and its effects.

One of the permanent features characterising the fictional vampire from its inception to its contemporary manifestations in literature is precisely the vampire's disaffection with the effects of ageing. Despite the passage of time, the vampire's appearance never betrays its chronological age, just as the mirror never renders back its actual reflection. Nevertheless, what is significant about the vampire in the context of ageing is that, in spite of the fact that the vampire is untouched by the effects of time, its appearance in relation to ageing has remarkably evolved from its early literary and cinematic manifestations up to now. Even if the vampire does not age in appearance, the way it has been presented has significantly transformed from a remarkable aged appearance during the Victorian period to outstanding youth, adolescence, and even childhood in its most recent portrayals in vampire fiction. It is worth noticing that early portraits of the vampire in Bram Stoker's Dracula and its cinematic counterpart in F.W.Murnau's expressionist film Nosferatu depict the vampire as an eminently old man who is truly even much older than he actually looks. It is thus significant to notice that, despite its disaffection with the visible effects of time, in early and Victorian portraits the vampire presents a rather aged appearance in comparison with contemporary manifestations in which the vampire looks significantly much younger even in both cases the vampire is precisely characterised by its incapacity to show its chronological age.

In addition to the vampire's disaffection with age, another feature that has traditionally characterised the vampire has usually been its lack of reflection in the mirror. In its origins, vampires did not use to reflect in mirrors because vampires were mirrors themselves, that is, double figures that reflected the darker side of Victorian society: its fears and anxieties. Vampires were thus conceived as mirror images in which individuals either failed or were reluctant to recognise themselves and were thus rejected as pathological as a result of a general fear of the other. As Leonard Heldreth argues, the vampire's traditional lack of reflection involves an absence of soul, thus underlining a loss of physical reality and presence within a morally God-orderly world. 
Lacking its reflection, the vampire embodies a mirror itself in which people's most frightening fears and concerns are reflected. The vampire is thus perceived as a Jungian shadow and, as such, it becomes part of the unconscious mind that amalgamates the individual's repressed instincts. In Jungian terms, the shadow remains in sharp contrast with the persona, the latter consisting in a mask that can be defined as the social face that the individual wishes to project to the world. The vampire thus embodies the individual's repressed self and, in Jungian terms, it becomes all shadow while it lacks its persona, that is, its public display, as its absence of reflection in the mirror ultimately shows.

Conversely, in contemporary manifestations, mirrors sometimes render back the reflection of vampires since it corresponds to an image that has been socially constructed and, therefore, is no longer rejected but is actually coveted and socially accepted. Drawing on Jung's terminology, rather than the individual's shadow, in contemporary fiction the vampire often reflects the individual's persona, that is, the individual's social mask and, therefore, its image sometimes even reflects back in the mirror. As a case in point, as Rosemary Guiley admits, Anne Rice's novels, which dismantled some traditional myths of the vampire lore, often feature vampires that have their reflection in the mirror. More recently, in Stephenie Meyer's Twilight saga (20052008), vampires also reflect in mirrors. As a matter of fact, in one scene of the first novel of the series, Bella Swan looks at Edward Cullen's reflection from the back seat of a car, stating that "he glared at me in the rear-view mirror" (385). In contemporary narratives, the vampire is no longer perceived as an embodiment of fear and anxiety but actually the vampire arises as an idealised self, even moving from villain to actual hero in an important number of contemporary narratives. The central role that the vampire plays in contemporary manifestations necessarily involves sympathy and even identification with this character on the part of the reader or the viewer. In this respect, it is important to notice how the attitude towards the vampire has changed through time, as people used to flee from Dracula or Nosferatu whereas younger generations even feel romantically attracted towards more contemporary vampires such as Louis in Anne Rice's novels or Edward in Stephenie Meyer's tetralogy. In the context of ageing studies, it is of great significance to notice that, as vampires have acquired more centrality in vampire fiction and the approach towards them has drastically changed, they have also turned significantly young in appearance in spite of still being actual embodiments of old age.

This gradual physical transformation of the vampire from old age to youth in appearance was clearly exemplified through the important contribution to the genre that Francis Ford Coppola's Bram Stoker's Dracula made in 1992. In this film, in spite of its actual old age as is customary, the vampire is intermittently portrayed as young and old in appearance in different scenes. Significantly enough, it is when the vampire presents an aged appearance that it displays its evilest nature and is consequently treated as an outcast. Conversely, when the vampire is portrayed as a young individual, its most humane side is brought to the fore and the audience can easily sympathise with the vampire. As a matter of fact, when Dracula imprisons Jonathan Harker in his castle, the 
vampire presents an aged appearance, while Dracula is mostly depicted as a young aristocrat when he is courting Mina. In this sense, Coppola's film contributes a postmodern paradigm of the vampire who transforms from old age into youth and vice versa, while it clearly influences the audience's changing attitudes towards the vampire depending on whether it looks old or young. Accordingly, Coppola's film involved a turning point that imbibed the legacy of the old tradition, whereby the vampire was depicted as rather aged, but it also paved the ground for subsequent exponents in vampire fiction that would portray the vampire as exponentially young in appearance.

Accordingly, it can be argued that in former times the vampire was a shadow, a reflection of the individual's repressed and utmost fears and the embodiment of the individual's anxiety towards ageing. By contrast, in contemporary narratives the individual projects its own image onto the vampire, who becomes a persona or a social mask, thus transforming the vampire into a personification of an idealised self whereby ageing is rendered invisible. Likewise, in some recent vampire narratives, the vampire might be enabled to look at its own reflection in the mirror precisely because its body rather projects a socially-accepted image as it is the reflection of the individual's idealised self. In this respect, following Margaret Gullette's premise that we are all ultimately 'aged by culture', it can be claimed that the youthful appearance of vampires in contemporary literature responds to the imagined self that the individual constructs on the basis of social demands in an attempt to modulate the self to suit social expectations.

Within the discourse of ageing and drawing on Jacques Lacan, Kathleen Woodward has postulated her thesis about 'the mirror stage of old age' whereby she identifies a point at which the processes of association and disassociation from the effects of old age can affect identity. Following Simone de Beauvoir's premises in The Coming of Age, Woodward admits that the individual does not perceive itself as old but it is rather the stranger within, the other internalised, that is labelled as old. In this respect, Woodward admits with Beauvoir that "the recognition of our own old age comes to us from the other, that is, from society" (1986: 104), hence we primarily identify ourselves as old through the social gaze. This premise mainly draws upon Lacan's theory of the mirror stage of infancy and Freud's theory of the uncanny, as Woodward underlines the connection between the individual's first and later stage in life due to both the infant and the ageing person constructing their own subjectivity through their awareness of difference. In this sense, as Kay Heath claims, while the child contrasts a fragmented experience of body with the mirrored whole and fantasises about unity, the old adult compares its image of disintegration in the mirror with an inner sense of wholeness. Consequently, the ageing individual is repulsed by the mirror image reflected in the mirror, the one that the social gaze ultimately renders back, which separates the individual from its inner self.

With regard to this sense of disparity between appearance and self, Simone de Beauvoir defended the need to identify with the ageing subject in order to avoid the sense of difference with which ageing has generally been associated. In this sense, Beauvoir refers to old age stating that "for the outsider it is a dialectic relationship 
between my being as he defines it objectively and the awareness of myself that I acquire by means of him, [thus concluding that] within me it is the Other - that is to say the person I am for the outsider - who is old: and that Other is myself" (1973: 420). Ageing is thus socially constructed and, within the social construct of age, Margaret Gullette has argued that the concept of age-as-loss is the premise that has mostly prevailed. Nonetheless, the individual's identification with its aged self should ultimately involve a sense of integrity and of fulfilment late in life that Leslie Fielder calls 'the eros of old age.' In this respect, from Fielder's perspective, while we are ageing, we gradually become what we once desired, thus hoping to attain the reintegration between image and inner self.

In vampire fiction, classical portrayals of the vampire as an aged individual lacking its reflection in the mirror place emphasis on the sense of disintegration as illustrated in Woodward's mirror of old age given the difference existing between self and the image it projects. Likewise, the vampire is incapable of recognising its non-existing ageing image in the mirror as the vampire is itself an embodiment of ageing that is constructed and, ultimately pathologised, through the social gaze. Alternatively, the vampire in contemporary fiction, even if apparently, rather seems to place more emphasis on the reintegration between image and self. Consequently, in some cases, the image of the vampire reflects in the mirror and its appearance rather than repulsive seems appealing and even idealised to others. Nonetheless, this reconciliation between self and image is effected at the expense of rendering ageing invisible as, having internalised an idealised image socially constructed, the individual never truly beholds its aged appearance in the mirror but rather a young, even if artificial, self that endows the individual with a merely simulated sense of reintegration. It can thus be claimed that, although the contemporary vampire appeals rather than repels and does not demand destruction but rather approval, it nevertheless gives rise to a dystopia of age rather than to a utopia of age.

Consequently, it can be argued that, although the paradox of age remains in Victorian as well as in contemporary vampire narratives - since the vampire persists through time without experiencing the effects of ageing - there has been a significant change in perspective. Victorian vampire fiction could be interpreted through the metaphor of the mirror of old age whereby the individual feels unable to identify with its aged reflection and, consequently, the image of the vampire never reflects in the mirror. By contrast, in contemporary vampire narratives, ageing is no longer pathologised but is rendered invisible and, therefore, virtually non-existent. Given its extraordinary youthful appearance in contemporary fiction, the vampire ultimately indulges in a sort of narcissism through its contemplation in the mirror, which arises as the mental corollary to its privileged social and physical condition. Likewise, in terms of sexuality, in Victorian vampire narratives, personal relations were governed by the power dynamics of dominance and submission personified by the relationship between the vampire and its victim, whereas, in the case of contemporary vampire fiction, a different sort of deviant sexuality is shown through total surrender to self-love and narcissism. In fact, in most contemporary vampire narratives, the vampire no longer 
feels the need to feed on humans. Hence, instead of indulging in the consumption of others as happens in Victorian vampire fiction, the vampire in contemporary narratives succumbs to self-consumption as a result of having absorbed the other into the self. In this respect, through the figure of the contemporary vampire, it can be argued that the individual has internalised the social gaze to the extent that it actually turns into the self, thus giving shape to an internalised social image that now reflects in the mirror.

\section{The evolution of the genre and analysis of examples}

In early characterisations displayed in nineteenth-century narratives, the vampire is clearly depicted as an embodiment of difference. As a matter of fact, the vampire was commonly characterised by eccentric habits, aristocratic origins, a markedly foreign accent and, particularly, a remarkably aged appearance in spite of being untouched by the passage of time. Hence, age became another marker of difference that used to characterise the Victorian vampire. Nonetheless, from its inception the literary vampire has undergone a significant process of rejuvenation, displaying a young and alluring appearance in contemporary narratives in spite of its actual age. It can thus be argued that the literary representations of the vampire - basically characterised by its true old age as well as by its great capacity to defy the effects of time - have evolved from presenting the vampire as an aged embodiment of difference and pathology to an exalted and even idealised individual even if at the expense of rendering any traces of ageing totally invisible. Hence, even though at first sight in contemporary fiction the vampire seems to exemplify an attempt at reconciling inner self and body image in old age, the remarkably young appearance that characterises vampires in contemporary manifestations underlines the social need to erase ageing in order to identify with the vampire. In fact, it can be argued that the gap existing between the vampire's inner self and the image it projects is even wider in contemporary portrayals of the vampire in comparison with early depictions whereby the vampire was mostly characterised by an aged appearance even if still being much older than it looked.

The nineteenth-century vampire for the most part projected an aged appearance, even if its image was still deceitful with regard to its true age. As a case in point, John Polidori's narrative "The Vampyre: A Tale", published in 1819, has traditionally been regarded as one of the first portrayals of a vampire in English literature, which laid the fundaments of the genre that would be subsequently cemented in Bram Stoker's novel. Polidori's tale revolves around Aubrey, a young Englishman, who becomes gradually initiated into the world of vice on behalf of Lord Ruthven, an eccentric aristocrat. The sharp contrast separating Aubrey's youth from Lord Ruthven's age is established from the very first pages when they both begin a tour across Europe. As a matter of fact, the following passage underlines the disparity between youth and innocence as opposed to old age and experience, thus underscoring that the experience of a lifetime, if used to immoral purposes, can easily corrupt the innocence of the youth: "[i]t was time for him [Aubrey] to perform the tour, which for many generations has been thought necessary to enable the young to take some rapid steps in the career of vice towards putting 
themselves upon an equality with the aged" (9). This rite of initiation into the corruptibility of ageing as a result of the intimate relationship established between Aubrey and Lord Ruthven is also addressed from a female perspective in Joseph Sheridan Le Fanu's novel of female vampires Carmilla, published in 1872, in which an ageing female vampire, Carmilla, also initiates young Laura into sexuality. Carmilla is middle-aged but, given her condition as a vampire, sometimes she suddenly undergoes a process of premature ageing as her health progressively declines as her pupil Laura notices: "[h]er face underwent a change that alarmed and even terrified me for a moment. It darkened, and became horribly livid; her teeth and hands were clenched, and she frowned and compressed her lips" (85). Hence, in spite of her alleged youthful appearance, Carmilla often falls prey to indispositions that betray her age and, by extension, her true nature.

These two vampire narratives underline one of the most enduring themes within vampire fiction, which is socially-perceived deviant sexuality. In addition to an apparent demonization of sexuality in general terms, vampire fiction, given the fact that the vampire is ultimately an aged individual, particularly appears to address the taboo of sex in old age. According to Herbert Covey, the perception of inappropriateness of sex in old age has traditionally been justified through physical limitations but, especially, through moral dictates. In Victorian times, sex in old age was generally stigmatised because it did not lead to procreation. In this respect, Karen Chase (2014) draws on nineteenth-century medical doctor, John Harvey Kellogg, and his use of the term 'senile sexuality' to refer to sex beyond the period of procreation, which was considered to be abnormal. Hence, the sexual discourse, which pervades vampire fiction, can be related to sexuality understood from the perspective of ageing as the vampire, who is a truly embodiment of old age, drains the life of the youth through an intercourse considered deviant that necessarily eludes the morally strict Victorian discourse. In fact, in the Victorian context, Karen Chase (2014) argues that aged sexuality is social inasmuch as vampires are characterised as old men and women that are starved for the life force of others. The equation of youth with fertility and the association of old age with sterility is essential to nineteenth-century vampire fiction as these narratives discuss the fluctuations between fertility/productivity and infertility/unproductivity through the intercourse between the aged vampire and its young victim. This deviant intercourse takes place through the vampire's use of its phallic fangs, which can be interpreted as a sign of male impotence in old age and betrays the sense of powerlessness and sexual decline with which society has traditionally associated the elderly. Similarly, the advances of some female vampires seem to correspond to a last resort to retain fertility and reject menopause, thus engaging in creating for themselves an alternative sort of menstruation that will allow them to remain young for time to come. Likewise, from a male perspective, through their alternative intercourse, female vampires literally embody the Freudian vagina dentata and thus stand for a sign of deviant sexuality on the part of aged women that proves to be particularly threatening to the male.

Although Bram Stoker's novel Dracula (1897) cannot be regarded as an early portrayal of the vampire myth, it has generally been acknowledged as the novel that 
consolidated the genre since it gave shape to a series of popular features that have often been attached to the figure of the vampire since late Victorian times. Dracula arises as the representative paradigm of the late Victorian vampire as an aged aristocratic man coming from a foreign country with an old regime that decides to settle down in Victorian England. Throughout the novel, even if the vampire's appearance never truly reflects its chronological age, its wrinkled and withered looks are often highlighted as the story unfolds. In fact, Jonathan Harker describes the vampire as follows soon after he first sets eyes on the count:

Within, stood a tall old man, clean-shaven save for a long white moustache, and clad, in black from head to foot, without a single speck of colour about him anywhere. He held in his hand an antique silver lamp, in which the flame burned without chimney or globe of any kind, throwing long, quivering shadows as if it flickered in the draught of the open door. The old man motioned me in with his right hand with a courtly gesture (15).

As the description above reveals, the vampire stands for an embodiment of difference as Harker's portrait of Dracula highlights its aristocratic manners and its eccentric outfit, which ultimately betrays its foreignness but, of special relevance, particularly given its vampiric nature, is the fact that Harker repeatedly draws attention to the vampire's old age.

The archetype of the aged Victorian vampire, mostly exemplified in Stoker's seminal novel, remains in sharp contrast with the blatantly young vampires that eventually populated twentieth-century vampire fiction. In this respect, as an outstanding turning point, Anne Rice's series following the first novel of the saga, Interview with the Vampire, published in 1976, contributed a major metamorphosis of the vampire as its appearance paradoxically transformed from age to youth even if the vampire has always been characterised by its disaffection with age. Much younger than Dracula, Lord Ruthven or Carmilla, to name a few examples of the classic nineteenthcentury vampire, contemporary vampires Louis and Lestat in Anne Rice's novels actually look in their mid-twenties. Louis himself gives evidence of this when he admits: "I was a twenty-five-year-old man when I became a vampire" (7). Moreover, Anne Rice should also be given the credit for introducing the figure of the vampire child, personified in the novel through Claudia. It is significant to notice that, as the appearance of the vampire becomes gradually younger, readers are also allowed to gain a deeper insight into the character's motivations, thus ultimately rendering the vampire more humane and prone to sympathy and identification on behalf of the reader. According to William Hugues, this gradual transformation responds to the fact that the vampire must be interpreted as the personification of social neuroses as well as the coded expression of more general cultural fears of which the author is an observer. In this respect, the evolving characterisation of the vampire in artistic manifestations necessarily responds to cultural conceptualisations of ageing throughout time.

Likewise, not only do Anne Rice's novels portray age identity as culturally and historically determined but they also unveil that age identity can be geographically conditioned. As a matter of fact, Louis, together with other vampires, decide to travel 
from New Orleans to Europe in order to find their own origins and gain further insight into their own identity as vampires. In this respect, as an important innovation in comparison with former portrayals of the vampire, in Anne Rice's novels vampires are endowed with a remarkable existentialist curiosity that leads them to question their existence and learn about the way of life of other vampires living in foreign countries. The geographic location determines the way vampires should behave and it also conditions the way vampires are perceived. In fact, in Interview with the Vampire Louis observes that in New Orleans vampires do not need to hide their need to kill because death appears to be so endemic there - owing to fever, plague, and crime - that the killing on behalf of vampires simply goes unnoticed. By contrast, during their trip to eastern Europe, Louis acknowledges that vampires should disguise the fact that they have to kill since the population in eastern Europe is familiar with the existence of vampires. Hence, not only does this difference condition the way vampires behave on both sides of the Atlantic but it also establishes a divergence in the way vampires are judged by human beings geographically. In Anne Rice's novel it is believed that, since it has been traditionally considered that vampires originated in Eastern Europe, their presence is more easily identified there, thus eastern Europeans are assumed to have more prejudices against vampires and are also less likely to be deceived by the youthful and innocent appearance of these young adult vampires. Given the fact that Europe has traditionally been known as the 'old' continent - where history and age seem to acquire more weight in comparison with the 'new' world - vampires, as actual embodiments of old age, appear to have a more widely-spread presence and, because of that, it is in the 'old' world that seems to prevail a greater concern about the difference between the vampire's old chronological age and its strikingly young appearance. In fact, quite tellingly, it can be acknowledged that the literary vampire, in origin, arose in the old continent.

The geographical difference conditioning the identity of vampires that prevails in Anne Rice's fiction was apparently taken over by Charlaine Harris' novel Dead Until Dark (2001), the first book within The Southern Mystery Series (2001-2013) - from which the popular TV series True Blood ultimately arose - as, in this saga, vampires differ among the four distinct divisions or clans that they populate across the United States. This series of novels revolves around a telepathic human waitress, young adult Sookie Stackhouse, who works in Louisana and solves different mysteries involving vampires, werewolves, and other supernatural creatures. As a postmodern paradigm in vampire fiction, some of the staple qualities that used to characterise the classic vampire are simply left behind. As a case in point, owing to the invention of synthetic blood, vampires no longer feed on human beings and this enables them to disclose their existence to the world while humans have to get used to their mutual coexistence. Likewise, also in sharp contrast with classic vampire narratives, in Charlaine Harris' novels it is actually humans who covet the blood of vampires once it is revealed that vampire blood has some extraordinary effects on humans as they become healthier, stronger, and more attractive. Hence, the tables are turned in this saga as humans drain vampires from their blood and, consequently, even if some humans still seek to destroy 
vampires or are reluctant to grant them rights, many humans actually aspire to emulate vampires. In terms of ageing, humans seek to take advantage of vampires in order to retain health and youth and, in this sense, the gap that formerly used to distinguish vampires from humans becomes increasingly blurred.

Hence, a clearly sharp contrast can be established between Bram Stoker's characterisation of the aged vampire and the young adult vampires populating Anne Rice's as well as Charlaine Harris' novels. As Martin Wood asserts, Anne Rice's novels - and one may add Charlaine Harris' saga as well - have forced readers to confront the core truths of the myth itself, finding themselves feeling an uneasy sympathy with the vampire and, therefore, these works have paved the ground for an important revision of our understanding of the vampire lore. In this context, in addition to endowing the vampire with a significant youthful appearance, Anne Rice's contribution to the genre also introduced other important innovations. As a matter of fact, in the first book of the series, Interview with the Vampire, Louis finds out that his body reflects in the mirror, which contributes a great change not only in the way the vampire is characterised but also in the way the vampire is perceived. Similarly, in Charlaine Harris' novels, vampires can also be photographed, thus placing emphasis on the vampire's socially appealing image. Consequently, it can be argued that in Anne Rice's novels the vampire begins to attract the readership's attention as the real hero of the narrative so that the reader can easily sympathise and identify with the vampire. In these narratives, vampires tend to subvert Woodward's theory of the mirror of old age as the vampire meets a faked unified reflection in the mirror, a virtual image of youth, which differs from any disintegrated or pathological reflection in old age. The vampire is no longer an embodiment of the fear of ageing - of the disintegration between self and image - but actually an idealised being whereby self and image integrate even if at the expense of concealing any trace of ageing. In this respect, Bryan Turner refers to the 'somatisation of the self', thus arguing that, in a culture in which the surface of the body is perceived as that which carries the signs of the individual's inner moral condition, ageing becomes something that has to be denied (1995: 257). Accordingly, the vampire reflects this 'somatisation of the self' and the social obsession with rendering ageing invisible in contemporary society.

Hence, as the vampire gradually attracts more sympathy and understanding on the part of the readership, it also acquires further importance as the actual protagonist of the story. In this respect, following the tendency initiated by Anne Rice's vampire novels, Stephenie Meyer's Twilight tetralogy (2005-2008) features a teenage vampire, Edward Cullen, who confesses he "was seventeen and dying of the Spanish influenza" (287) when his father Carlisle transformed him into a vampire in the summer of 1918, although the action of the novel is set in the year 2005. In Meyer's novels, the vampire is portrayed as a thoroughly sympathetic character to the extent that the heroine, Bella Swan, falls in love with him but, again, if the vampire is to attract the admiration of the audience, it seems to be not only because of its good nature but also because of its outstanding youthful appearance that renders the traces of ageing totally invisible. The vampire is no longer stigmatised, as happened in Victorian times, but it rather arises as 
an embodiment of an idealization - of the integration between the self and its reflection - even if that reflection mostly responds to social demands of rendering age invisible.

Likewise, in addition to featuring outstandingly young vampires in their adolescence, contemporary vampire fiction has also often portrayed vampires as children, taking Anne Rice's character of Claudia, the vampire child, as a clear prototype. If portraits of adolescent vampires seem to defy Woodward's theory of the mirror of old age, the figure of the vampire child appears to further transform Lacan's theory of the infant's fragmented self that fantasises about the integrated self as perceived in the mirror. Paradoxically, in the case of narratives featuring vampire children, since the vampire child is aware of its integrated self as an aged individual, it no longer perceives an integrated reflection in the mirror but rather a childish image, which, from its own perspective as an adult, actually becomes a fragmented image, that is, an infantilised reflection that contrasts with its inner self, which is remarkably aged. Likewise, the vampire's childish appearance in spite of its blatant senescence literally brings to mind the well-known metaphor of ageing as a second childhood when two different stages of life join together. The figure of the vampire child that has populated many contemporary vampire narratives further elaborates on the schism between image and self, body and mind, thus uniting the fragility and innocence of a child in appearance and the wisdom and experience that age may bring about. As a case in point, Laurell K. Hamilton's novel Guilty Pleasures, published in 1993, which gave rise to her series of novels featuring Anita Blake as a vampire hunter, portrays a female vampire child who happens to be the master of the vampires that populate the city and is described in the novel as follows:

She had been about twelve or thirteen when she died. Small, half-formed breasts showed under a long flimsy dress. It was pale blue and looked warm against the total whiteness of her skin. She had been pale when alive; as a vampire she was ghostly. Her hair was that shining white-blond that some children have before their hair darkens to brown. This hair would never grow dark. (71)

Similarly, Swedish author John Ajvide Linqvist's successful novel Let the Right One In, published in 2004, tells the story of Oskar, a twelve-year-old child bullied at school, who meets the twelve-year-old looking Eli, who, in turn, happens to be a twohundred-old vampire forever frozen in late childhood. The proliferation of vampire children in contemporary narratives within vampire fiction still further corroborates a significant diachronic evolution from portraits of aged vampires in Victorian fiction to adolescent and infant vampires in contemporary narratives as the figure of the vampire becomes more sympathetic and appealing to younger audiences. The image of the vampire as an embodiment of the aged has moved from a sign of difference and pathology to blatant invisibility as the effects of ageing are totally banished from the picture in an attempt at aiming at a faked integration between inner self and image projected. As ageing remains invisible in the vampire, it no longer becomes a sign of difference and from this follows that the young vampire is exalted as an embodiment of integration with which the audience can fantasise. 


\section{Conclusions}

Following this chronological transformation of the portrayal of the literary vampire as an embodiment of the aged individual, it can be argued that there is a general tendency to move from portraits of pathology to depictions of invisibility in relation to old age, thus showing that age identity is historically influenced, culturally determined, and even geographically conditioned. In Victorian times, the vampire's aged appearance arose as a sign of difference and its image was not reflected in mirrors because it truly became an embodied mirror reflecting people's fears and, among them, people's dread of ageing. Drawing on Woodward's premises of the mirror of old age, the vampire thus became a sign of disintegration, an embodiment of the void between body and inner self, and people's failure at recognising the disintegrated reflection of their own self in the mirror. Progressively, as the vampire grew younger in appearance in its characterisation in contemporary narratives, it also acquired more centrality in the plot, even turning into the hero of the story. The young vampire becomes the embodiment of the integrated image between the body and the inner self and, consequently, its image can have its reflection in the mirror in many contemporary manifestations as the vampire becomes an idealised and a socially-accepted fantasy. Nonetheless, this faked integration between the image and the inner self ultimately renders age invisible. Accordingly, it can be claimed that the contemporary literary vampire does not truly illustrate an integrated image through which the subject is enabled to identify, as it rather seems to respond to a social and cultural dystopia of eternal youth instead of portraying age as a desirable stage in life in which the individual can truly attain selffulfilment.

\section{References}

Auerbach, Nina (1995): Our Vampires, Ourselves. Chicago: University of Chicago Press.

Beauvoir, Simone de (1973): The Coming of Age. Trans. Patrick O'Brian. New York: Warner Paperback Library.

Butler, Robert (1987): “Ageism”. The Encyclopedia of Aging. New York: Springer, 22-23.

Chase, Karen (2009): The Victorians and Old Age. Oxford: Oxford University Press.

Chase, Karen (2014): “'Senile' Sexuality”. In K. Boehm, A. Farkas and A.-J. Zwierlein, eds., Interdisciplinary Perspectives on Aging in Nineteenth-Century Culture. London and New York: Routledge, 132-146.

Cicero, Marcus Tullius (2009): Letters of Marcus Tullius Cicero with His Treatises on Friendship and Old Age; Letters of Pliny the Younger. The Five Foot Shelf of Classics, IX. New York: Cosmos.

Cole, Thomas (1983): "The 'Enlightened' View of Aging: Victorian Morality in a New Key". The Hastings Center Report (13): 34-40.

Coppola, Francis Ford, dir. (1992): Bram Stoker's Dracula. Columbia Pictures. Film.

Covey, Herbert (1991): Older People in Western Art and Society. New York: Praeger. 
Fielder, Leslie (1986): "More Images of Eros and Old Age: The Damnation of Faust and the Fountain of Youth". In K. Woodward and M. Schwartz, eds., Memory and Desire: Aging, Literature and Psychoanalysis. Bloomington: Indiana University Press, 37-50.

Guiley, Rosemary Ellen (2005): The Encyclopaedia of Vampires, Werewolves and Other Monsters. New York: Visionary Living.

Gullette, Margaret Morganroth (1997): Declining to Decline: Cultural Combat and the Politics of Midlife. Charlottesville: University Press of Virginia.

Gullette, Margaret Morganroth (2004): Aged by Culture. Chicago: University of Chicago Press.

Hamilton, Laurell K. (1993): Guilty Pleasures. London: Headline.

Harris, Charlaine (2001): Dead Until Dark. New York: Ace Books.

Heath, Kay (2006): "In the Eye of the Beholder: Victorian Age Construction and the Specular Self". Victorian Literature and Culture 34(1): 27-45.

Heldreth, Leonard (1999): "S.P. Somtow's Timmy Valentine: The Vampire as Archetype and Fragmented Reflection". In L. Heldreth and M. Pharr, eds., The Blood is the Life: Vampires in Literature. Bowling Green: Bowling Green State University Popular Press, 121-137.

Hugues, William (2000): "Fictional Vampires in the Nineteenth and Twentieth Centuries". In D. Punter, ed., A Companion to the Gothic. Oxford: Blackwell, 143-153.

Katz, Stephen (1996): Disciplining Old Age: The Formation of Gerontological Knowledge. Charlottesville: University Press of Virginia.

Lindqvist, John Ajvide (2007): Let the Right One In. London: Quercus.

Mangum, Teresa (2005): "Growing Old: Age". In H. F. Tucker, ed., A Companion to Victorian Literature. London: Blackwell, 97-109.

Meyer, Stephenie (2008): Twilight. New York: MT Books.

Murnau, F.W. dir. (1922): Nosferatu, eine Symphonie des Grauens. Films Art Guild. Film.

Polidori, John (2007): "The Vampyre: A Tale". In D.S. Davies, ed., Children of the Night: Classic Vampire Stories. London: Wordsworth, 7-24.

Rice, Anne (2001): Interview with the Vampire. London: Sphere.

Sheridan Le Fanu, Joseph (2007): "Carmilla". In D.S. Davies, ed., Children of the Night: Classic Vampire Stories. London: Wordsworth, 65-130.

Small, Helen (2007): The Long Life. Oxford: Oxford University Press.

Stoker, Bram (2000): Dracula. London: Wordsworth.

Turner, Bryan (1995): "Aging and Identity: Some Reflections on the Somatization of the Self". In M. Featherstone and A. Wernick, eds., Images of Aging: Cultural Representations of Later Life. London and New York: Routledge, 245-260.

Wood, Martin (1999): "New Life for an Old Tradition: Anne Rice and Vampire Literature". In L. Heldreth and M. Pharr, eds., The Blood is the Life: Vampires in Literature. Bowling Green: Bowling Green State University Press, 59-78.

Woodward, Kathleen (1986): "The Mirror Stage of Old Age". In K. Woodward and M. Schwartz, eds., Memory and Desire: Aging, Literature and Psychoanalysis. Bloomington: Indiana University Press, 97-113. 